\title{
Correction to: Providing Compassionate End of Life Care in the Setting of Mechanical Circulatory Support
}

\author{
Anna Joong $^{1} \cdot$ Sabrina F. Derrington ${ }^{2} \cdot$ Angira Patel $^{1} \cdot$ Philip T. Thrush $^{1} \cdot$ Kiona Y. Allen $^{3} \cdot$ Bradley S. Marino $^{3}$
}

Published online: 5 February 2020

(C) Springer Science+Business Media, LLC, part of Springer Nature 2020

\section{Correction to: Current Pediatrics Reports (2019) 7:168-175 https://doi.org/10.1007/s40124-019-00206-4}

The original version did not include the correct affiliations as noted by the authors in their proofs which can be seen below.

The online version of the original article can be found at https://doi.org/ 10.1007/s40124-019-00206-4

\section{Anna Joong}

ajoong@luriechildrens.org

1 Division of Cardiology, Ann \& Robert H. Lurie Children's Hospital of Chicago, Feinberg School of Medicine, Northwestern University, 225 E Chicago Ave, Box 21, Chicago, IL 60611-2991, USA

2 Division of Critical Care, Division of Palliative Care, Ann \& Robert H. Lurie Children's Hospital of Chicago, Feinberg School of Medicine, Northwestern University, 225 E. Chicago Ave, Box 73, Chicago, IL 60611, USA

3 Divisions of Cardiology and Critical Care Medicine, Ann \& Robert H. Lurie Children's Hospital of Chicago, Feinberg School of Medicine, Northwestern University, 225 E Chicago Ave, Box 21, Chicago, IL 60611-2991, USA 